\title{
Artigo
}

\section{O processo de socialização do Conselho Sul-americano sobre o Problema Mundial das Drogas}

\author{
The socialization process of the South American World Drug Problem Council \\ DOI: $10.5752 /$ P.1809-6182.2016v13.n2.p56
}

Helena Salim de Castro ${ }^{1}$

\section{RESUMO}

Recebido em: 10 de março de 2016 Aprovado em: 07 de julho de 2016

O tráfico de drogas é um problema que acomete todos os paises do subcontinente sul-americano, exigindo que os Estados adotem politicas conjuntas para combatê-lo. A criação do Conselho Sul-Americano sobre o Problema Mundial das Drogas (CSPMD) ocorre neste contexto. O presente artigo se propôs analisar quais foram os mecanismos e condiçóes que permitiram e incentivaram os paises da América do Sul a cooperarem e participarem deste Conselho. Após uma explanação das abordagens que algumas vertentes teóricas possuem sobre o papel das Instituiçóes Internacionais, optou-se por utilizar a ideia de Processo de Socialização, a qual converge algumas abordagens racionalistas com o construtivismo. Concluiu-se que tanto os fatores abordados nas teorias racionalistas, quanto os enfatizados pelos construtivistas foram importantes, juntamente com um contexto favorável, para o processo de cooperação que emergiu na criação do CSPMD.

Palavras-chave: Instituiçóes Internacionais. Processo de Socialização. CSPMD.

\section{ABSTRACT}

Drug trafficking is a problem that affects all countries of the South American subcontinent, requiring states to adopt joint policies to combat it. The creation of The South American World Drug Problem Council (CSPMD) occurs in this context. This study aimed to analyze what were the mechanisms and conditions that allowed and encourage the countries of South America to cooperate and participate on this Council. After an explanation of the approaches that some theoretical aspects have on role of international institutions, it was decided to use the idea of Socialization Process, which converges some rationalistic approaches with constructivism. It was concluded that both factors discussed in rationalist theories, as emphasized by the constructivists were important, along with a favorable context, for the process of cooperation that emerged in the creation of CSPMD.

Keywords: International Institutions. Socialization Process. CSPMD.

1. orcid.org/0000-0003-3059-2150 


\section{Introdução}

O abuso de drogas é uma constante preocupação das sociedades e países, levando a debates de âmbito doméstico e internacional sobre os mecanismos necessários para impedir o consumo e comércio destas substâncias ilícitas. A partir da década de 1970 o tráfico de drogas passou a ser considerado uma ameaça nacional, principalmente, nos Estados Unidos. O governo norte-americano direcionou seus esforços para combater o comércio de drogas nas Américas, o qual entrou na agenda de segurança dos países do continente como uma "nova ameaça", tanto à sua populaçáo, quanto ao eficaz desenvolvimento do Estado.

Medidas repressivas foram utilizadas pelos Estados Unidos, dando início à chamada "guerra às drogas", como foi proclamada ainda no governo de Richard Nixon (1969-1974) e impulsionada pelo presidente Ronald Reagan (1981-1989). Como também, a percepção acerca do tráfico de drogas como uma "nova ameaça" aos países do continente americano gerou a necessidade de cooperação e diálogo para o tratamento desta problemática.

O primeiro organismo criado para este fim foi, ainda no final da década de 1980, a Comissáo Interamericana para o Controle do Abuso de Drogas (CICAD), pertencente à Organização dos Estados Americanos (OEA). Esta Comissão, nos anos iniciais, funcionou como um órgão de diálogo a fim de incentivar a cooperação entre os países. Logo passou a propor políticas que visavam tanto à redução da oferta, com programas alternativos, como a redução da demanda de drogas, incentivando programas de apoio aos dependentes dentro dos Estados-membros (SILVA, 2013).

Porém, o fato desta Comissão não propor a discussão de temas importantes para o tratamento do problema das drogas, como o Plano Colômbia ${ }^{2}$

2. O Plano Colômbia consistiu de um pacote de auxílio financeiro, ofertado pelos Estados Unidos em parceria com países europeus e o Japão, a fim de destruir as plantaçôes de folha de
(2000), programa que foi motivo de preocupação e divergências entre os países na América do Sul, e também sofrer influência direta dos Estados Uni$\operatorname{dos}^{3}$, gerou a necessidade dos países sul-americanos a estabelecer um órgão que atendesse as necessidades específicas da região. Assim, emerge em abril de 2010 o Conselho Sul-Americano para o Problema Mundial das Drogas (CSPMD).

O objetivo deste artigo, portanto, é analisar quais os fatores que influenciaram na cooperação entre os países da América do Sul para a criação do CSPMD. A compreensão dos mecanismos e condiçóes que garantiram a participação dos países em um conselho voltado para a questâo do problema das drogas na região exigirá a utilização conjunta de abordagens racionalistas e construtivistas, exercício de análise presente no conceito de Processo de Socialização.

Para alcançar este objetivo principal o artigo será dividido em três sessóes, além desta introdução e das considerações finais:

- As Análises Teóricas das Instituiçóes Internacionais - nesta primeira sessão serão apresentadas, de forma geral, as análises de três teorias das Relaçôes Internacionais sobre a importância das Instituiçóes Internacionais, a fim de termos um panorama sobre esta discussão na disciplina;

- O Conselho Sul-Americano sobre o Problema Mundial das Drogas (CSPMD) - o objetivo desta sessão é apresentar o CSPMD, quando foi criado, quais seus objetivos e as diretrizes de seu Plano de Ação; e

\section{- O Processo de Socializaçáo do CSPMD}

- por último faremos a análise do processo de socialização desta instituição, observando

coca na Colômbia e combater os grupos organizados ligados com o tráfico de drogas.

3. Desde a criaçáo da CICAD, é um representante norte-americano que ocupa o cargo de secretário executivo da Comissáo, o mais importante da mesma. 
os mecanismos e condiçóes que favorecem a cooperação entre os Estados membros.

\section{As análises teóricas das instituições internacionais}

Os estudos em Relações Internacionais abordam uma temática que é alvo de muitas críticas e discussões entre vertentes, que é a existência e efetividade das Instituições Internacionais e Regimes Internacionais. Discute-se a real funcionalidade dos mesmos e como os Estados, considerados soberanos no sistema internacional, veem essas instituiçóes e se relacionam com elas.

Beth Simmons e Lisa Martin (2002) desenvolveram um estudo em que buscaram retratar a evolução do tema das Instituiçóes Internacionais, as abordagens teóricas que foram surgindo, principalmente depois da Segunda Guerra Mundial, e os efeitos destas Instituições no sistema internacional e nas relaçóes que possuem com os Estados.

Os primeiros estudos que surgiram no pós-guerra focaram-se em Organizaçôes Internacionais (OIs) formais, principalmente nos órgãos das Nações Unidas, analisando as regras e normas, as relações destas OIs com as políticas domésticas e as decisóes governamentais dos Estados. A perda de influência de algumas instituiçóes internacionais na década de 1970, consequência de crises sistémicas (crise do sistema financeiro mundial), aumentou o "fosso" entre as políticas internacionais e organizaçôes formais, dando origem aos estudos de Regimes Internacionais, os quais permitiam uma compreensão mais ampla sobre governança internacional (SIMMONS; MARTIN, 2002).

Carvalho (2010) também observa as diversas teorias e suas justificativas para sustentar as hipóteses acerca da funcionalidade de um regime internacional. O autor utiliza das análises de Stephen Krasner, um importante teórico das Relaçóes Internacionais, para abordar a temática acima apresentada. No seu trabalho apresenta uma definição de regimes internacionais como "conjuntos de princípios, normas, regras e procedimentos de tomada de decisão implícitos ou explícitos em torno dos quais as expectativas dos atores convergem em uma determinada área das relaçóes internacionais" (CARVALHO, 2010, p. 209-210).

A concepção de regimes internacionais, apontando a existência de normas e regras para o comportamento dos Estados, preencheu a lacuna existente nos aspectos técnicos das OIs formais, dando possibilidade para a análise de instituiçôes formais e informais (SIMMONS; MARTIN, 2002, p.194).

Assim, a partir da década de 1990 um novo termo foi utilizado, o de Instituiçóes Internacionais, definindo, de modo geral, "conjuntos de regras destinados a governar o comportamento internacional" (SIMMONS; MARTIN, 2002, p.194, tradução minha). Diante disso, Simmons e Martin (2002) apresentam as concepçôes e análises de algumas abordagens teóricas, das relaçōes internacionais, sobre as Instituiçôes.

O principal debate nas Relaçóes Internacionais ocorre entre as teorias Realista e Liberalista (ou Institucionalista), assim como suas vertentes (debate Neo-Neo). Esta disputa entre as duas correntes teóricas também perpassa a discussão sobre as Instituições Internacionais.

Os teóricos realistas, principalmente aqueles considerados tradicionais (Morgenthau e Carr), não negam por completo a existência de Instituições Internacionais, apenas as consideram como uma medida de segundo plano para os interesses e poder estatais (SIMMONS; MARTIN, 2002). Os Estados utilizariam dessas instituições unicamente com o intuito de alcançarem seus próprios interesses - maior ganho de poder relativo. Os realistas tradicionais também apontam que as Instituições Internacionais apenas são estáveis devido à atuação dos poderes dominantes (SIMMONS; MARTIN, 2002, p. 195). 
Esta abordagem recebeu críticas dos teóricos institucionalistas, os quais sustentam a tese de que as Instituições Internacionais importam e podem ser autônomas às açôes dos Estados. Tais teóricos apontam que o realismo é incapaz de explicar a participação dos países em Instituiçôes que não convergem com os interesses dos mesmos.

Em resposta a esta primeira crítica, Kenneth Waltz (2000), um realista estrutural, faz um esforço de mostrar que o realismo ainda é uma teoria válida ${ }^{4}$. O autor confirma o pressuposto de que as Instituições são criadas para atender os interesses dos Estados mais poderosos, por isso estes se esforçam em manter tais estruturas. Portanto, enquanto as Instituições proverem os interesses dos Estados, a sua composição original será mantida, pois estas têm pouca (ou nenhuma) autonomia de ação (WALTZ, 2000).

Em oposição a esta abordagem, emergem os contrapontos dos teóricos neoinstitucionalistas. Robert Keohane (2002), um dos principais autores desta vertente, após as críticas dos teóricos neorrealistas, apresenta um trabalho em que explora o contexto de interdependência em que as instituiçôes

4. Waltz (2000) utiliza a OTAN (Organização do Tratado do Atlântico Norte) para comprovar a atual validade dos pressupostos de sua vertente teórica. Para os realistas o fim da Guerra Fria significaria o fim desta organização, pois náo haveria mais interesse da grande potência (Estados Unidos) em mantê-la. Porém, mesmo com o fim da ameaça comunista a OTAN permaneceu existindo, representando, então, um possível contraponto para a teoria realista. Não obstante, Waltz (2000) aponta que não só a permanência, como a expansão da OTAN (um maior número de países passou a fazer parte da organização), ajudam a reforçar seus argumentos. O desmantelamento da OTAN ocorreria em muitos custos e prejuízos, uma vez que se trata de uma grande organização, com um grande número de funcionários que desejam sua perpetuação. Além disso, com as mudanças no sistema internacional as instituiçóes também se alteram, os interesses dos Estados que as criaram se modificam gerando outros focos de atuação. Isto ocorreu com a OTAN, os interesses norte-americanos de manter influência nas políticas externa e militar dos países europeus fez com que a organização adotasse um novo foco, mas ainda atendendo os objetivos da grande potência (WALTZ, 2010). operam. Não obstante, o autor afirma que estes conceitos não são os mais importantes na política mundial contemporânea, aceitando certa semelhança de sua teoria com o realismo.

Na década de 1970, Keohane e Joseph Nye desenvolvem o conceito de "interdependência complexa": "um tipo ideal para analisar as situaçóes de contatos e temas transnacionais múltiplos em que a força não é um instrumento de política utilizado" (KEOHANE, 2002, p. 2, tradução minha) $)^{5}$. Os autores afirmam que as relaçóes de interdependência entre os atores se dão em uma situação assimétrica, a qual gera recursos de poder para os mesmos (sejam Estados ou atores não estatais), sendo diante deste contexto de interdependência assimétrica que as Instituiçóes Internacionais emergem (KEOHANE, 2002).

Os teóricos (neo) institucionalistas acreditam que as Instituições Internacionais ajudam a reduzir os custos da aplicação das regras, promovem a troca de informações entre os atores, o que reduz as assimetrias entre os mesmos, e reduzem os problemas de ação coletiva, incentivando os atores a manter seus compromissos internacionais.

No escopo (neo) institucionalista o compromisso dos Estados com os acordos firmados através de uma instituição é garantido por dois fatores:

- a reciprocidade; e

- a reputação. Espera-se que as instituiçóes monitorem os acordos firmados sob sua égide, enquanto a aplicaçáo dos mesmos ficaria de responsabilidade dos Estados. Os atores também estão atentos a sua reputação internacional, sendo coagidos a manter um acordo firmado com outras partes, a fim de não sofrer represálias futuras, decorridas de uma possível violação (KEOHANE, 2002).

Para Keohane (2002), além dos interesses ma-

5. " $[\ldots]$ an ideal type for analyzing situations of multiple transnational issues and contacts in which force is not a useful instrumento f policy" (KEOHANE, 2002, p.2). 
teriais que levam um Estado a criar e se inserir sob os auspícios de uma instituição, devem ser consideradas as identidades compartilhadas pelos atores e as ideias e expectativas que os mesmos têm com relação à cooperação promovida pela participação na instituição.

O papel das identidades e ideias na promoção da cooperação entre atores, estatais ou não-estatais, é melhor trabalhado pelos teóricos do construtivismo. Esta teoria emerge como um contraponto às duas apresentadas anteriormente, constituindo uma nova divisão, agora entre racionalistas e construtivistas.

Para os autores da vertente construtivista o conjunto de normas e regras que limitam e moldam o papel dos Estados são de extrema importância. Há uma mútua constituição de identidades na relação entre as Instituiçôes Internacionais e os Estados, sendo que os interesses e as identidades deste último podem ser alterados ao participar das instituiçôes (FINNEMORE; SIKKINK, 2001).

Os construtivistas buscam compreender o papel das ideias na elaboração das regras e normas que vão promover a cooperaçáo entre os Estados e como as políticas domésticas interferem neste processo, que por sua vez também moldam as características das Instituiçôes Internacionais (SIMMONS; MARTIN, 2002).

Contrapondo as teorias neoliberais, o construtivismo assinala o papel das instituiçóes em distribuir responsabilidades entre os atores, dando aos mesmos, valores normativos e significativos (BARNETT; FINNEMORE, 1999, p.700). Há uma preocupação em mostrar a importância das Organizaçôes Internacionais para além da promoçáo da cooperaçáo.

Barnett e Finnemore (1999) fazem uma análise, baseados no institucionalismo sociológico, sobre o comportamento das Organizaçóes Internacionais após seu processo de criação. Em vez de focar apenas nos motivos e processos que geram a criação destas instituiçóes, os autores argumentam que, após serem estabelecidas, estas burocracias possuem poderes independentes dos Estados. Devido a sua autoridade racional-legal e o controle que possuem sobre técnicas de informação, as Organizaçôes Internacionais canalizam seu poder em diversas direçóes, criando regras e conhecimento, ao mesmo tempo que estão propensas a comportamentos disfuncionais e patológicos (BARNETT; FINNEMORE, 1999, p.699).

O poder independente das Organizações Internacionais emana de três fontes:

- a capacidade de classificar e organizar as informaçôes e conhecimentos, criando categorias de ação e de atores;

- a fixação de significados no mundo social; e

- a articulação e difusáo de novas normas, princípios e atores (BARNETT; FINNEMORE, 1999, p.710). Estas capacidades exercidas pelas OIs, acompanhada da concepção de que as burocracias são eficazes, devido às especialidades e regras que as constituem, garante legitimidade às Instituiçóes perante os Estados. Não obstante, estas mesmas fontes de poder podem gerar disfunçóes, e até patologias, nas Organizaçóes Internacionais. Algumas destas disfunções ocorrem devido:

- à restrição dos objetivos das instituições, motivada pela incorporação de regras e normas; - ao fato das burocracias acreditarem que conhecimentos e técnicas são aplicados universalmente; - à normalização de certos desvios, que acaba por modificar seus objetivos;

ao isolamento que possuem com relação às demandas e críticas de atores externos; e

- à falta de coerência organizacional, gerando disputas políticas dentro da própria burocracia (BARNETT; FINNEMORE, 1999, p. 720-724)

No entanto, embora o construtivismo seja por 
vezes apresentado na literatura com um viés totalmente oposto às teorias racionalistas (realismo e liberalismo e suas vertentes), há autores que apontam as vantagens de utilizar ambas abordagens, principalmente nas análises das Instituições Internacionais. É este uso qualitativo das prerrogativas das duas teorias que utilizaremos para analisar o Conselho Sul-Americano sobre o Problema Mundial das Drogas.

Os construtivistas Fearon e Wendt (2002) realizaram um trabalho a fim de mostrar que ambas as abordagens (racionalista e construtivista) podem ser utilizadas de forma complementar. Mesmo havendo diferenças entre ambas, utilizá-las conjuntamente como ferramentas analíticas, e não como teorias de política internacional, aumenta o poder explicativo da pesquisa.

Os autores apontam que o construtivismo também aceita a existência de fatores materiais, porém a importância destes é dependente das ideias. E o racionalismo, por sua vez, também assinala que as ideias têm um papel essencial, visto que estas em conjunto com os interesses dos atores geram as ações (FEARON; WENDT, 2002).

A utilizaçáo conjunta do racionalismo e do construtivismo é útil para analisar a importância e o papel das normas. Para os racionalistas as normas têm uma função regulatória para o comportamento dos atores, enquanto os construtivistas veem as normas como constitutivas das identidades e interesses dos mesmos. Para os autores, ambas as compreensões são úteis. É impossível analisar as políticas mundiais, principalmente o papel das instituiçōes internacionais, apenas com uma lente (FEARON; WENDT, 2002).

Esta complementariedade do racionalismo com o construtivismo está presente nas análises sobre o processo de socialização das Instituições Internacionais, um conceito utilizado, principalmente, pelos construtivistas sociais.

É com base neste conceito de socialização, que a princípio é entendido como "o processo de indução dos atores às normas e regras de uma dada comunidade" (ZURN; CHECKEL, 2005, p.1.046, tradução minha ${ }^{6}$ ), que analisaremos os mecanismos e condiçôes que geraram o processo de cooperação entre os países sul-americanos para a criaçáo do Conselho Sul-Americano sobre o Problema Mundial das Drogas (CSPMD).

No entanto, a priori, realizaremos uma breve explanação sobre CSPMD. A fim de compreender o vem a ser este Conselho, quais seus objetivos e meios de ação.

\section{O CSPMD}

O Conselho Sul-Americano para o Problema Mundial das Drogas (CSPMD) é uma instancia recém-criada, no âmbito da Uniāo das Naçōes Sul-Americanas (UNASUL). Este conselho emergiu em um contexto de implementação de organismos regionais na América do Sul no início dos anos 2000, em que os países desta sub-região buscavam uma maior articulação e cooperação interna para tratar os problemas regionais de forma autônoma e garantindo a soberania estatal frente, principalmente, às intervençôes extra regionais, com destaque aos Estados Unidos. A própria UNASUL emergiu neste período, tendo seu Tratado Constitutivo ${ }^{7}$ assinado em 23 de maio de 2008 pelos 12 Estados independentes da América do Sul.

Ainda no ano de 2008, em 16 de dezem-

6. " $[\ldots]$ the process of inducting actors into norms and rules of a given community" (ZURN; CHECKEL, 2005, p.1046)

7. O Objetivo principal da UNASUL é: "construir, de maneira participativa e consensuada, um espaço de integração e união no âmbito cultural, social, econômico e político entre seus povos, priorizando o diálogo político, as políticas sociais, a educaçấo, a energia, a infra-estrutura, o financiamento e o meio ambiente, entre outros, com vistas a eliminar a desigualdade socioeconômica, alcançar a inclusão social e a participaçáo cidadá, fortalecer a democracia e reduzir as assimetrias no marco do fortalecimento da soberania e independência dos Estados" (UNASUL, 2008, p. 6 e 7). 
bro, foi criado o Conselho de Defesa Sul-Americano (CDS), um organismo também pertencente à UNASUL, que tem como objetivo promover a cooperação entre os países da regiáo no âmbito da defesa, a fim de criar uma identidade regional e promover uma indústria bélica na América do Sul. A ênfase dada por este organismo à defesa na regiáo tem o intuito de separar os assuntos de segurança pública, os quais devem ser tratados internamente pelos países, ou então através de outros organismos regionais, que não o CDS. Assim, ainda se via a necessidade de criar um organismo que impulsionasse a cooperação na região para solucionar um problema que acomete todos os países, o tráfico de drogas, tal organismo seria o CSPMD.

A intenção de se debater o tema das drogas entre os países na América do Sul já estava presente no Tratado Constitutivo da UNASUL (2008). No artigo 3 onde são apresentados os objetivos específicos, o item $\mathrm{g}^{8}$ conversa sobre a necessidade de coordenação entre os organismos especializados dos Estados membros em fortalecer a luta contra diversas ameaças que acometem a regiáo, entre elas o "problema mundial das drogas" (UNASUL, 2008, p.9).

Em agosto de 2009 durante a III Reunião Ordinária do Conselho de Chefas e Chefes de Estado e de Governo, realizada em Quito (Equador), foi proposta a criação do organismo, ainda com o nome de Conselho Sul-Americano de Luta contra o Narcotráfico. Porém, a fim de evitar o caráter repressivo e a lógica de segurança optou-se por mudar o nome do mesmo.

A mudança ocorreu após as I, II e IV Reu-

8. Transcrição completa do item: "a coordenação entre os organismos especializados dos Estados Membros, levando em conta as normas internacionais, para fortalecer a luta contra o terrorismo, a corrupçáo, o problema mundial das drogas, o tráfico de pessoas, o tráfico de armas pequenas e leves, o crime organizado transnacional e outras ameaças, assim como para promover o desarmamento, a não proliferação de armas nucleares e de destruição em massa e a desminagem" (UNASUL, 2008, p.9). nióes de Vice-ministros e Especialistas do Conselho, nos dias 28 e 29 de fevereiro, 4 de março e 7 e 8 de abril de 2010, que culminaram na assinatura do Estatuto do Conselho Sul-Americano para o Problema Mundial das Drogas (CSPMD), conformando-o em uma instancia permanente "de consulta, cooperação, e coordenaçáo para enfrentar o problema mundial das drogas" (UNASUL, 2010a, p.1, tradução minha).

Os princípios que regem as ações do CSPMD seguem aqueles propostos pela UNASUL, de respeito à soberania dos estados e não intervenção nos regimentos internos dos mesmos, além da cooperação entre os países para solucionar o problema das drogas, atuando de forma equilibrada nos níveis de redução da oferta e redução da demanda. Os objetivos gerais estabelecidos no Estatuto sáo:

a. Propor estratégias, planos e mecanismo de coordenação e cooperação entre os Estados Membros para incidir de forma integral em todos os âmbitos da problemática, de acordo com o estabelecido no artigo 5 do Tratado Constitutivo da UNASUL;

b. Construir uma identidade sul-americana para enfrentar o problema mundial das drogas, tomando em conta os compromissos internacionais nesta matéria, assim como as características nacionais e sub-regionais, para fortalecer a unidade da América do Sul;

c. Fortalecer as relaçóes de amizade e confiança através da cooperação interinstitucional entre as agências especializadas de cada país, para fazer frente ao problema mundial das drogas, mediante o fomento do diálogo e de busca de consensos;

d. Promover a articulação de posiçóes de consenso em foros multilaterais em matéria de drogas, como fundamentado no artigo 14 do Tratado Constitutivo da UNASUL (UNASUL, 2010a, p.2, tradução minha).

Além destes objetivos gerais, o CSPMD contém 10 objetivos específicos. Dentre os quais propôem a cooperação na capacitação das instituiçóes e dos profissionais dedicados ao problema das drogas 
e o intercâmbio de informaçôes e práticas desenvolvidas para enfrentar esta questão, além de destacarem-se os objetivos que abordam a possibilidade de harmonização das normas penais, civis e administrativas dos Estados e que propõe a cooperação judicial, policial e das unidades de inteligência financeira efetiva, a fim de responder aos delitos relacionados ao problema das drogas (UNASUL, 2010a).

Combinado à aprovação do Estatuto do Conselho na Reunião Extraordinária de Chefas e Chefes de Estado e de Governo da União das Nações Sul-Americanas, realizada dia 4 de maio de 2010, na cidade de Los Cardales, Argentina, foi estabelecido o Plano de Açáo do CSPMD, o qual consta com cinco linhas de ação por âmbito de competência:

- reduçáo da demanda;

- desenvolvimento alternativo, integral e sustentável;

- redução da oferta;

- medidas de controle; e

- lavagem de ativos. Em cada linha de ação há uma série de objetivos que as permeiam.

Ademais, no Plano de Ação está prevista a necessidade de Coordenação e Fortalecimento Institucional entre os membros do Conselho, a fim de promover estratégias de comunicação sobre o problema das drogas, além de fomentar os Observatórios Nacionais sobre Drogas para impulsionar uma rede de compartilhamento de informaçôes, que auxilie na formulação de políticas eficazes para o controle do abuso de drogas na região (UNASUL, 2010b).

No Estatuto do Conselho há menção a possibilidade de criação de grupos de trabalho para executar as atividades do Plano de Ação. Os quais foram estabelecidos pelos membros do CSPMD a fim de implementar as diretrizes do Plano de Ação, sendo que para cada grupo há um ou mais países coordenadores:

- redução da demanda - Argentina;
- desenvolvimento alternativo, integral e sustentável - Peru;

- redução da oferta - Chile;

- medidas de controle - Colômbia;

- lavagem de ativos - Peru e Venezuela;

- fortalecimento institucional e harmonização legislativa - Uruguai e Argentina (VELASCO, 2012).

Nos primeiros anos do Conselho, observou-se um certo dinamismo e impulso nas suas açóes. Com o estabelecimento de projetos e a criação dos grupos de trabalho. Na VI Cúpula Presidencial da UNASUL em novembro de 2012, na cidade de Lima (Peru), realizou-se uma reunião preliminar do CSPMD - Reunião de Instância Executiva - em que se aprovou a extensão do mandato dos grupos de trabalho para o ano de 2013 (VELASCO, 2013).

Houve uma intensa participação da Venezuela, engajando-se nas atividades do Conselho. Durante a Reunião de Instância Executiva também foram discutidas a viabilidade das propostas requeridas pelo governo venezuelano:

- "estabelecer um 'Sistema de Intercâmbio de Informação sobre Drogas em nível da UNASUL”; - a "realização de um Diplomado sobre Vigilância e Controle para a Prevençáo do Tráfico de Ilícitos”; e

- "estabelecer um Centro de Estudos Sul-Americano de Drogas" (VELASCO, 2013, p.4).

Embora estas propostas tenham sido aprovadas numa reuniấo posterior, em 5 dezembro de 2012, o que se observou a partir do ano seguinte foi uma diminuição do dinamismo do Conselho. O objetivo de criação de um grupo ad hoc para avaliar os Planos de Ação não se concretizou e o CSPMD ainda não logrou alcançar uma posição comum entre os países membros para fazer frente nas discussões sobre o problema das drogas nas Naçóes Unidas (TOKATLIAN; COMINI, 2016, p.3; VELASCO, 2014). 


\section{O processo de socialização do CSPMD}

Uma vez apresentado os objetivos de criação do Conselho Sul-Americano sobre o Problema Mundial das Drogas, analisaremos como o conceito de processo de socialização pode auxiliar na compreensão dos fatores que levaram os países da região à cooperarem para a criação deste organismo.

De acordo com Zurn e Checkler (2005), autores que discutem o conceito de socialização, as Instituiçôes Internacionais seriam uma espécie de gatilho para este processo, as quais se valem de mecanismos causais, que ligam condiçóes iniciais específicas com resultados específicos, "empurrando" os atores ao aceite de suas normas.

O objetivo principal de apresentar este conceito é "construir pontes" entre o racionalismo e o construtivismo, pois de acordo com Zurn e Checkler (2005), ambas vertentes se complementam para uma análise eficaz dos motivos e processos que geram a cooperaçáo entre os atores dentro de uma determinada instituição.

Os autores apresentam quais seriam os mecanismos causais deste processo de socialização, dividindo-os entre dois tipos:

- "barganha" - seriam as ameaças e promessas que constrangem o comportamento dos atores; e

- a "argumentação" - refere-se aos ensinamentos, empíricos e normativos, a fim de modificar as crenças dos atores (ZURN; CHECKLER, 2005).

Johnston (2001), em sua análise do processo de socialização, aponta dois "microprocessos", que em parte se equivalem aos já apresentados:

- a influência social - mecanismo que utiliza de recompensas e puniçóes sociais; e

- a persuasão - processo de mudança de opinião e comportamento sem o uso da coerção e ganhos materiais. A persuasão se daria por três formas, através de:

* um "intenso processo de cognição, reflexão e argumentação sobre o conteúdo da nova informação";

* um "relacionamento afetivo com o persuasor"; e

* quando "a persuasão é uma característica do próprio persuadido" (JOHNSTON, 2001, p.496-497; - tradução minha). ${ }^{9}$

Para Johnston (2001, p.500, traduçáo minha) $)^{10}$, nas relações internacionais, o "microprocesso" mais relevante para se analisar os processos de interação social que promovem a cooperaçáo é "o desejo de maximizar o status, a honra, o prestígio [...] e o desejo de evitar a perda deste status, a vergonha ou humilhação, além de outras sansões sociais".

Percebe-se que para este conceito de socializaçáo se aceita a abordagem institucionalista de que a reputação tem influência na manutenção do compromisso estatal com a cooperação. Como também, os construtivistas estão certos ao afirmar a importância da construção social e do compartilhamento de ideias, para a promoção da cooperação entre os atores (JOHNSTON, 2001).

Ao trazer estes conceitos de socialização para a análise do Conselho Sul-Americano sobre o Problema Mundial das Drogas (CSPMD), podemos observar como tal abordagem auxilia no entendimento do processo que levou os Estados a buscarem uma cooperação para o enfrentamento do problema das drogas.

9. "[...] a high intensity process of cognition, reflection, and argument about the contente of new information"; "her/his affect relationship to the persuader"; "the persuasuviness of a message may be a function of characteristics of the persuadee her/himself." (JOHNSTON, 2001, p.496-497).

10. "The most importante microprocess of social influence [...] is the desire to maximize status, honor, prestige [...] and the desire to avoid a loss of status, shaming, or humiliation and other social sanctions." (JOHNSTON, 2001, p.500) 
Como apresentado, as Instituiçóes Internacionais funcionam como gatilhos dos mecanismos de socialização, permitindo um ambiente em que estes influenciam no comportamento dos atores. A criação do CSPMD surgiu com o intuito de estabelecer um conjunto de políticas de enfrentamento do problema das drogas que fossem únicas para todos os países sul-americanos, e para que isto se concretize há uma série de princípios e normas que devem ser respeitadas por todos os membros do Conselho - como o respeito à soberania dos Estados e a atuação conjunta em todos os âmbitos da luta contra as drogas.

Todos os países se propuseram a participar do CSPMD, mesmo que a princípio as políticas internas de combate ao problema das drogas se diferenciem entre si e daquelas propostas pelo Conselho. Para os grandes países, como o Brasil, a participação em um organismo regional como este, embora não atenda diretamente seus interesses ${ }^{11}$, é requerida para que o mesmo esteja a par das discussóes de seu entorno geográfico e, caso queira, maximizar sua influência na região, como um possível líder.

Para os pequenos países, como o Uruguai, a participação no CSPMD é importante para angariar apoio em suas políticas internas ${ }^{12}$ de controle do abuso de drogas e tentar influenciar este organismo a adotar medidas mais alternativas que vão de encontro com aquelas realizadas no âmbito doméstico. Assim como, a não participação no Conselho causaria desconforto para o país no contexto sub-regional, uma vez que a proposta inicial de criar o CSPMD é se desvincular da lógica repressiva das políticas implementadas há décadas pelos Estados Unidos.

11. No Brasil o combate ao problema das drogas ainda está muito ligado à lógica da repressáo. Além da utilizaçáo das Forças Armadas brasileiras para o combate ao tráfico de entorpecentes ilegais, na legislação do país os mecanismos para classificar um indivíduo abordado com drogas como usuário ou traficante são suscetíveis de dúvidas.

12. Em dezembro de 2013 o governo do Uruguai aprovou a legalizaçáo da produção, distribuiçáo e venda de maconha no país, sob o controle estatal (URUGUAI..., 2013).
Além dos mecanismos causais, o conceito apresentado por Zurn e Checkler (2005) leva em consideração as condiçóes sob as quais o processo de socialização ocorre, as chamadas condiçóes de escopo. Para os autores há uma série de condiçôes que possibilitam as Instituições Internacionais desencadearem os mecanismos que levam à socialização, e estas podem ser alocadas em quatro grandes grupos:

- "propriedades das Instituições Internacionais [...] que desencadeiam a socialização";

- "propriedades dos sistemas políticos e agentes que se tornam socializados [...]";

- "propriedades das questóes e normas sobre as quais a socialização acontece [...]"; e

- "propriedades da interação entre socialização e agentes socializados [...]" (ZURN; CHECKLER, 2005, p.1055, tradução minha). ${ }^{13}$

Estas condiçôes são percebidas ao analisar a criação do CSPMD. O problema do tráfico e consumo de drogas já vinha desde o final da década de 1980 e começo de 1990 alarmando os países sul-americanos. A expansão da "guerra às drogas", liderada pelos Estados Unidos, para o resto do continente impulsionou os países a criarem políticas de combate a esta "nova ameaça", e também gerou debates e discussóes incentivando a cooperação hemisférica. Tal contexto percebemos que se encaixa no grupo 3 das condiçóes para ocorrência do processo de socialização.

No início dos anos 2000 temos a emergência de governos considerados de centro-esquerda na América do Sul. Estes novos atores políticos, que viam com desconfiança a influência de potências extrarregionais, em especial os Estados Unidos, perceberam a necessidade de criar organismos específi-

13. "This list can be grouped in four more general headings: properties of international institutions [...] that trigger socialization; properties of the political systems and agentes tha become socialized [...]; properties of the issues or norms regarding wich socialization takes place [...]; and properties of the interaction between socializing and socialized agentes [...]" (ZURN; CHECKLER, 2005, p.1055). 
cos para a regiáo, que os permitissem resolver seus problemas de forma autônoma. Esta característica compóe a condição de número 2 para o processo de socialização, proposta por Zurn e Checkler (2005).

As condiçôes do Grupo 1 (formação de instituições atentas aos problemas específicos da região), apontada pelos autores, também são percebidas na análise do CSPMD. O enfrentamento do problema das drogas também sofreu influência deste novo regionalismo que se iniciava no século XXI. Com o intuito de se desvincularam da lógica repressiva das políticas de combate ao tráfico, promulgadas pelos Estados Unidos, as quais não consideravam os problemas específicos e características da região, os países sul-americanos decidiram criar um organismo regional próprio, o CSPMD.

Portanto, compreendemos que a utilizaçáo do conceito de processo de socializaçáo para analisar o CSPMD é útil pois esta abordagem permite uma "dupla interpretação" da dinâmica de socialização das Instituições Internacionais (ZURN; CHECKLER, 2005). Ao levar em consideração tanto os aspectos das correntes racionalistas (a preocupação dos Estados em manter e maximizar o status e o papel das recompensas e puniçôes) como os da vertente construtivista (se atentar ao entendimento e compreensão dos valores em comum e das preferências dos atores) torna-se mais compreensível os motivos que levaram os países sul-americanos, com diferenças de políticas internas no tratamento do problema das drogas, a impulsionar um mecanismo regional que tem o objetivo de coordenar as ações e promover uma cooperaçáo neste âmbito.

\section{Considerações finais}

O papel e importância das Instituiçóes Internacionais é um tema frequente nas discussōes teóricas de Relações Internacionais. Há vertentes, aquelas originadas do realismo clássico, que afirmam que as instituiçóes apenas servem aos interesses dos grandes Estados, portanto não possuem autonomia própria. Por outro lado, embora afirmando a náo centralidade das Instituiçóes Internacionais, os teóricos neoinstitucionalistas apontam para uma maior importância destas para cooperação entre os atores no sistema internacional, afirmando que as instituições são capazes de moldar o padrão de ação de seus membros. E, diferentemente destas teorias de abordagem racionalista, a vertente construtivista aponta para a importância do contexto social, das ideias e identidades na formação das Instituiçóes Internacionais.

Embora existam divergências entre as abordagens racionalista e construtivista, há um esforço na literatura de Relaçóes Internacionais em apresentar as vantagens de utilizar ambas as ferramentas analíticas para estudar e entender o processo de socialização das Instituições Internacionais. É esta "dupla interpretação" que utilizamos no artigo, com o objetivo de compreender quais os mecanismos e o contexto que permitiu os países da América do Sul a criarem o Conselho Sul-Americano sobre o Problema Mundial das Drogas (CSPMD).

Ao analisar o processo de socialização em volta da criação do CSPMD percebemos que diversos fatores, que são empregados por abordagens analíticas distintas, tiveram influência no incentivo à cooperação entre os países na regiáo sul-americana:

- o constrangimento em participar do Conselho; - o interesse de manter influência e de uma possível maximização do status na América do Sul; - o compartilhamento da percepção da droga como uma ameaça regional; e

- o interesse conjunto de criar um mecanismo próprio de luta contra o problema da droga. Alguns destes fatores ( $\mathrm{a}$ e b) podem ser relacionados às abordagens racionalistas, em que o mecanismo causal seria a "influência social", enquanto outros (c e d) convergem com as 
abordagens construtivistas, com a "persuasão" como mecanismo causal.

Além destes "mecanismos causais" que impulsionam a socialização, as condiçóes para que este processo ocorra também são importantes. $\mathrm{O}$ CSPMD emergiu em um contexto favorável. A preocupação geral com o problema das drogas e a ascensão de governos com tendências de esquerda permitiram a criaçấo de um organismo regional com objetivo de desenvolver políticas alternativas ao enfrentamento do tráfico e ao consumo de drogas na América do Sul.

\section{Referências}

BARNETT, Michael N.; FINNEMORE, Martha. The Politcs, Power, and Pathologies of International Organizations. International Organization, vol. 53, No. 4 (Autumn, 1999), p. 699-732.

CARVALHO, E.Stephen Krasner. In: LIMA, Marcos Costa et al. (Ed). Clássicos das Relaçốes Internacionais. São Paulo: Hucitec, 2010.

FEARON, James; WENDT, Alexander. Rationalism v. Constructivism: A Skeptical View. In: CARLSNAES, Walter; RISSE, Thomas; SIMMONS, Beth A. (Ed.). Handbook of international relations. London: Sage Publications, v. 1, 2002, p. 52-72.

FINNEMORE, Martha; SIKKINK, Kathryn. Taking Stock: The Constructivist Research Program in International Relations and Comparative Politics. Annual review of political science, v. 4, n. 1, 2001, p. 391-416.

JOHNSTON, Alastair Iain. Treating international Institutions as social environments. International Studies Quarterly. v. 45, n. 4, p. 487-515, Dec. 2001.

KEOHANE, Robert O. Introduction: from interdependence and institutions to globalization and governance. KEOHANE, Robert. Power and governance in a partially globalized world. New York: Routledge, 2002, p.1-24.

SILVA, Lopes Luiza. A Questão das drogas nas relaçôes internacionais: uma perspectiva brasileira. Brasília: Fundação Alexandre de Gusmão, 2013.

SIMMONS, Beth A.; MARTIN, Lisa L. International organizations and institutions. In: CARLSNAES, Walter; RISSE, Thomas; SIMMONS, Beth A. Handbook of international relations. London: Sage Publications, v. 1, p. 192-211, 2002.

TOKATLIAN, Juan Gabriel; COMINI, Nicolás. "Guerra contra las drogas": ‘se puede modificar el paradigma internacional? Notes Internacionales. Barcelona: CIDOB, n. 149, Mayo 2016.
UNIÓN DE NACIONES SURAMERICANAS. Tratado constitutivo da Uniấo de Naçóes Sul-Americanas. Brasília: UNASUR, 2008. Disponível em: < http://www.itamaraty.gov. br/images/ed_integracao/docs_UNASUL/TRAT_CONST_ PORT.pdf > . Acesso em: 8 maio 2015

UNIÓN DE NACIONES SURAMERICANAS. Estatuto del consejo suramericano sobre el problema mundial de las drogas. Quito: UNASUR, abr. 2010a. Disponível em: < http://www.unasursg.org/images/descargas/ESTATUTOS\%20CONSEJOS\%20MINISTERIALES\%20SECTORIALES/ESTATUTO\%20CONSEJO\%20DE\%20DROGAS.pdf>. Acesso em: 8 maio 2015.

UNIÓN DE NACIONES SURAMERICANAS. Plan de acción del Consejo Suramericano sobre el problema mundial de las drogas. Los Cardales: UNASUR. Maio 2010b.

URUGUAI aprova legalizaçâo do cultivo e venda da maconha. [S.1.]: BBC BRASIL, 10 dez. 2013. Disponível em: < http:// www.bbc.com/portuguese/noticias/2013/12/131210_uruguai_aprova_maconha_mm $>$. Acessado em: 16 jul. 2015.

VELASCO, Carla Alvarez. El Consejo Suramericano sobre el problema mundial de las drogas de la UNASUR: logros y desafios 2012-2013. [S.1.]: IDPC. 2013. Disponível em: < https://dl.dropboxusercontent.com/u/64663568/library/El-CSPMD-de-la-UNASUR-Logros-y-desafios-2012-2013.pdf>. Acesso em: 10 jul. 2016.

VELASCO, Carla Alvarez. El Consejo Suramericano sobre el problema mundial de las drogas de la UNASUR En el $^{2}$ limbo? mar. 2014. Disponível em: < https://dl.dropboxusercontent.com/u/64663568/library/Informe_UNASUR_Marzo-de-2014.pdf>. Acesso em: 10 jul. 2016.

VELASCO, Carla Alvarez. Los retos que enfrenta el Consejo Suramericano sobre el problema mundial de las drogas de UNASUR. London: IDPC, jul. 2012.

WALTZ, Kenneth N. Structural realism after the Cold War. International security, v. 25, n. 1, p. 5-41, Summer 2000.

ZÜRN, Michael; CHECKEL, Jeffrey T. Getting socialized to build bridges: constructivism and rationalism, Europe and the nation-state. International Organization, v. 59, n. 4, p. $1045-$ 1079, 2005. 